\title{
VEGA INCLÁN Y LAS CASAS MUSEO: UN CONCEPTO INÉDITO DEL TURISMO CULTURAL EN LA ESPAÑA DE ALFONSO XIII
}

\author{
Soledad Pérez Mateo \\ Conservadora de Museos del Ministerio de Cultura y Deporte \\ Doctora en Historia del Arte \\ Museo Nacional de Arqueología Subacuática ARQUA
}

\section{RESUMEN}

Este trabajo analiza, en el contexto de la España Alfonsina, la figura de Vega Inclán como museólogo visionario que introduce una tipología museística antes desconocida en España, la casa museo, instaurando una museografía contextual que ya era habitual en el mundo anglosajón. La creación de las casas museo a través de sus proyectos de la Casa y Museo del Greco en Toledo, la Casa de Cervantes en Valladolid y el Museo Romántico de Madrid, se justifica, en estrecha relación con el pensamiento institucionista, por la necesidad de construir una identidad nacional y el deseo de honrar a unos nuevos héroes que deberían ser conocidos dentro y fuera de nuestras fronteras. Para ello recurre a la recreación de unos espacios domésticos enfatizando el valor del contexto al integrar el inmueble y el entorno, poniendo en estrecha relación la museología y el turismo a través del turismo experiencial.

Palabras clave: Vega Inclán; casa museo; recreación; museografía contextual; turismo.

\section{Vega Inclán and House Museums: A new concept of cultural tourism in Spain in the first of Alfonso XIII}

\section{ABSTRACT}

This paper analysis, in Spain of Alfonso XIII, the figure of Vega Inclán as a visionary museologist who introduced, for the first time in Spain, an unknown type of museum: the house museum, using a contextual museography that was already well known in the AngloSaxon world. The creation of house museums with his projects of the House Museum of

Fecha de recepción: 1 de marzo de 2017.

Fecha de aceptación: 5 de septiembre de 2017.

Museo Nacional de Arqueología Subacuática ARQUA. Paseo del Muelle Alfonso XII, 22. 30202 Cartagena MURCIA (España).E-mail: soledad.perez.m@mecd.es 
Greco in Toledo, House Museum of Cervantes (Valladolid) and the Romantic Museum of Madrid was influenced by Free Educational Institute and it was justified by the necessity of building a national identity and the wish to honor new heroes who should be known both inside and outside of our borders. To achieve it, Vega Inclán recreated domestic spaces focusing in the value of context by integrating the building and its surroundings, bringing together museology and tourism, through an experiential tourism.

Keywords: Vega Inclán; house museum; recreation; contextual museography; tourism.

\section{DON BENIGNO DE LA VEGA INCLÁN: UN MUSEÓLOGO Y UN CONTEXTO}

Benigno Vega Inclán y Flaquer, II Marqués de la Vega Inclán (Valladolid, 29 de junio de 1858- Madrid, 6 de enero de 1942) es una personalidad trascendente para el conocimiento de la historia de la cultura española del primer tercio del siglo XX que desde su muerte permaneció prácticamente en el olvido. Será en 1965 cuando Vicente Traver le dedique el primer estudio biográfico y se despierte el interés por su figura. Traver fue durante quince años el arquitecto de la Comisaría Regia de Turismo materializando los numerosos proyectos de Vega Inclán, de quien fue su amigo y confidente. Esta cercanía explica que Traver subraye la emoción como el componente fundamental de los proyectos vegainclanianos. Su biografía se completa con las aportaciones de Menéndez Robles (2000a, 2000b, 2004, 2006, 2008, 2014, 2015) y de Lavín Berdonces (2007c, 2008, 2016, 2017), cuyas trayectorias profesionales se encuentran vinculadas a las casas museo impulsadas por don Benigno, por lo que no es casual que el marqués sea objeto de sendas Tesis Doctorales. Por un lado, Menéndez Robles, en "Un mecenas de la España alfonsina: el II Marqués de la Vega Inclán (1858-1942)”, traza su trayectoria vital detallando sus diferentes etapas profesionales, que van desde el incansable viajero hasta el descubridor del patrimonio artístico y del turismo, que impulsa difundiendo los valores paisajísticos y monumentales de España. Aunque Menéndez Robles considera que la introducción en España de la casa museo se debe a Vega Inclán y a su proyecto de la Casa y el Museo del Greco (Menéndez Robles, 2009), no hay que olvidar que ya en 1875 Mariano Pérez Mínguez (Valladolid, 1809-1887) recreó, con motivo del 275 aniversario de la publicación del Quijote, el interior de la Casa de Cervantes de Valladolid ${ }^{1}$ con muebles y objetos antiguos y que mantendrá abierta hasta su muerte. Pérez Mínguez es una figura poco conocida y, en su faceta de anticuario, se adelanta unos años a Vega Inclán en la concepción de lo que sería una casa museo "pues hasta en la habitación que sirvió de dormitorio [...] se había colocado un lecho del siglo XVII y sillas y adornos de la misma época", dando a la estancia "un ambiente que la imaginación completaba hasta comprenderle como el respirado por el grande y a la vez modesto maravilloso escritor [...]" (Urrea, 2005: 46 y ss). La Sociedad Cervantina de Valladolid, denominada "La Casa de Cervantes", se creó

1 En 1866 la casa se había reconocido como habitada por Cervantes durante su segunda estancia vallisoletana, señalada con el número 14, lo que fue aceptado oficialmente colocando el Ayuntamiento una placa conmemorativa. Véase Pollán Palomo, 2016. 
en 1875 y adornó las estancias con muebles, armas, pinturas, libros antiguos y ediciones del Quijote que habían sido reunidos por el propio Pérez Mínguez. Urrea señalaba que la casa disponía de edificio, patronato, reglamento de funcionamiento, presidente, socios, biblioteca, publicaciones, actividades, entrada de pago y libro de firmas, de manera que se puede hablar de la existencia de un plan director museístico (Urrea, 2005: 50 y ss.). Aunque se cobraba la visita los ingresos fueron insuficientes porque tenía apenas visitantes. Al desaparecer la Sociedad Cervantina en 1887 la Casa de Cervantes fue deteriorándose hasta que intervino Vega Inclán en 1912, cuando informa al rey Alfonso XIII del estado de ruina en que se encuentra el edificio y le propone comprarlo para crear una biblioteca y un museo. Por otro lado, Lavín Berdonces, quien fue directora del Museo del Greco entre 2003 y 2007, en su Tesis Doctoral "La creación de los museos de ambiente en España: La Casa y el Museo del Greco de Toledo" ha ido desmontando el mito de la casa del Greco defendiendo que es el primer museo de ambiente creado en España que materializa un proyecto político nacional y que su relevancia marcó una línea de actuaciones museográficas nacionales e internacionales en la primera mitad del siglo XX. La propia Lavín señala que no estamos ante la casa del Greco (Caballero y Lavín, 2007, Lavín y Caballero, 2007a; Lavín y Caballero, 2007b), sino ante el Museo del Greco, excluyendo toda mención a la “casa" y denominándola la "casa inexistente" (Lavín, 2013: 178), quedando únicamente la cocina como una suerte de vestigio arqueológico vegainclaniano. Pero todavía hoy acuden visitantes a Toledo preguntando por la casa del Greco.

En 1999 don Benigno será objeto de la primera exposición que se organice en España en torno a su figura, denominada "Exposición permanente sobre el fundador del Museo Romántico: don Benigno de la Vega-Inclán”, ubicada en la planta baja del Museo Romántico, su tercera casa museo después de la del Greco y la de Cervantes. Dicha exposición, comisariada por Torres González, directora del Museo Romántico desde 1997 hasta 2010, analiza a Vega Inclán como creador del Museo Romántico, su faceta coleccionista y amante del arte, y su relación con los miembros de la Generación del 98, que influye en su modo de ver y valorar el patrimonio y el paisaje acuñado por el círculo institucionista (Torres González, 1998a, 1998b, 1999a, 1999b). No hay que olvidar que el marqués, nacido en las postrimerías del Romanticismo y que conoció la Restauración y el Desastre del 98, tuvo estrecha relación con la filosofía de la Institución Libre de Enseñanza y con el Regeneracionismo. La crisis finisecular explica en parte esa necesidad de Vega Inclán de recuperar unos iconos nacionales que permitieran a España disponer de unas señas de identidad propias, en un afán de propaganda patria. Su labor desarrollada al frente de la Comisaría Regia tiene en cuenta esa influencia institucionista. Como señalaba Pérez de Ayala: "Sin duda en la formación de la sensibilidad del marqués de la Vega Inclán influyeron los graves y delicados maestros de la Institución Libre de Enseñanza (ese lar de alta cultura al cual se debe casi todo lo que hay de saludable y puro en la España de hoy)" (Pérez de Ayala, 1991: 206-207). El espíritu regeneracionista en torno al problema de España y la fragilidad del nacionalismo español, tendría su eje en la dialéctica casticismoeuropeización. El monarca Alfonso XIII, de talante regeneracionista, desempeñaría un protagonismo central en la concepción y el desarrollo de la política cultural en el exterior.

La riqueza del legado cultural vegainclaniano es innegable y en este aspecto han insistido numerosos autores, siendo una de las cuestiones más polémicas la de su actividad 
como marchante, que hay que entenderla en el contexto histórico en el que se produjo, en el que no existía una normativa estatal que regulase el tráfico de bienes del patrimonio histórico español en el ámbito de la propiedad privada, tal y como recogen Kagan (2013) y Merino de Cáceres y Martínez Ruiz (2012). En efecto, este aspecto, que no deja de ser controvertido, ya fue señalado en los años cincuenta del siglo XX (Gaya Nuño, 1958 y 1964) y reafirmado por Álvarez Lopera (1987 y 2008). También se ha insistido en su escasa profesionalidad en el desarrollo de la gestión de la cultura y del turismo (Moreno Garrido, 2004; Villaverde, 2014) porque, con su nombramiento como Comisario Regio, cargo que desempeñó entre 1911 y 1928, eclipsará la labor de otra entidad paralela, la Dirección General de Bellas Artes, creada en 1903 como rama específica de la administración pública en materia de cultura, autorizada por la Ley de Presupuestos de 26 de diciembre de 1914 y desarrollada en las Reales Órdenes de 26 de enero y 12 de febrero de 1915. Lavín va más allá al identificar a Vega Inclán con el personaje de Catón San Martín, el chamarilero de la novela "Toledo la despojada" (1924), del escritor Félix Andrés Urabayen (Lavín, 2016: 351-361).

El propósito de este estudio es examinar dos aspectos que quizá no han sido lo suficientemente valorados y que posicionan claramente la relación vegainclaniana entre el turismo y la museología. De un lado, el marqués como creador de la primera casa museo en España en un inmueble del siglo XV, la Casa del Greco, en Toledo, concluida en 1907 y donada al Estado en 1942, aunque ya estaba abierta al público² ${ }^{2}$ Don Benigno es pionero en la génesis de una museografía ${ }^{3}$ contextual basada en la recreación, que será el recurso expositivo que goce de fortuna en gran parte de las casas museo españolas a lo largo del siglo XX. La casa museo, como tipología museística inédita en España, es interpretada como un lugar dedicado a un personaje convertido en símbolo. De otro, el potencial que Vega Inclán vio en las casas museo como configuradoras de lo que Poria, Biran y Reichel denominaban turismo patrimonial, definido por dos elementos: el identitario y el emocional o afectivo. Las expectativas que depositó en este patrimonio a la hora de impulsar o diversificar el turismo fueron significativas. Hasta cierto punto es una situación que se retroalimenta: el patrimonio cultural configura el destino turístico, y el turismo magnifica la capacidad de atracción de dicho patrimonio. El marqués era consciente del potencial de las casas museo como fortalecedoras de una identidad, como lieux des mémoires, empleando la expresión popularizada a partir de los años ochenta por el historiador francés Pierre Nora, en tanto que el imaginario colectivo puede representar e identificar los valores nacionales. Por entonces, en un momento histórico en el que se estaban afianzando los nacionalismos del siglo XIX y del XX, los bienes se asociaban a un concepto reduccionista de monumento, tal y como definió Riegl en 1903, noción que será sustituida a partir de los años sesenta por la de "patrimonio histórico" (Choay, 1992 y 2009). ¿Cómo convertir una casa en un museo?, ¿cómo patrimonializarla y darle un estatus museal?, ¿cómo transformarla en musealia (Desvallées y Mairesse, 2011: 251-269)?, ¿cómo contar la historia de la vida de quienes vivieron en ella?, ¿cómo representar esta cultura material historizada?, ¿hasta qué punto se considera relevante un espacio doméstico como paradigma de un modo de vida, de un individuo o

2 El Museo del Greco se abre al público en 1911, quedando visitable junto a la Casa.

3 El término museografía es el más empleado en el ámbito francés, pero en los países anglosajones se prefiere museum practice y los museólogos del Este, el de museología aplicada. 
una clase social, de cierta pretensión estética, de un momento histórico concreto?, ¿en qué sentido documenta la realidad partiendo de la conciencia de que no es la realidad misma?.

Don Benigno estableció el punto de partida para tener en cuenta las dinámicas territoriales y las relaciones e interdependencias entre el patrimonio y el turismo, en definitiva sobre la funcionalidad turística del patrimonio cultural. Su política turística fue significativa en el proceso de desarrollo del paisajismo moderno. En esta línea contribuirá a la valoración de Toledo como arquetipo paisajístico vinculado al Greco en el imaginario nacionalista español de la primera mitad del siglo XX. La Casa del Greco se inserta dentro de las actuaciones de la Comisaría Regia de Turismo para difundir los valores monumentales y paisajísticos de la ciudad de Toledo. La especificidad del patrimonio no residirá en su valor económico, sino cultural y en concreto, en su dimensión simbólica e identitaria. Esta idea de la valoración simbólica y patrimonial de determinados lugares es una línea de investigación que se ha ido desarrollando en las últimas décadas, en relación con los nacionalismos y los procesos de construcción nacional contemporáneos. Vega Inclán era consciente de que tanto la casa como el museo servirían para la construcción de una identidad nacional que era necesario recuperar. Esta idea se relaciona con los planteamientos del Regeneracionismo, que propugnaba la valoración de la cultura popular y de lo español en tanto que raíces de una identidad nacional. Para lograr esa regeneración la educación será uno de los pilares básicos. Y don Benigno conocía la labor docente de Cossío al frente del Museo Pedagógico Nacional. Vega Inclán, como Comisario Regio, estará muy interesado en la educación de las clases populares (Cabanillas García, 2012). Junto a la vocación de los institucionistas por abrirse hacia Europa está la de recuperar los signos del pasado nacional para configurar el punto de apoyo para la regeneración, camino que conduce al Greco.

El turismo patrimonial tal y como lo entiende Vega Inclán está ligado a las casas museo, idea hasta entonces desconocida en España. La museografía contextual implica el edificio, las colecciones y el entorno como unidades expositivas. El contexto adquiere un estatus museal. Para ello se sirve de la recreación, anticipándose a un tipo de montaje expositivo que continúa en la actualidad. Huelga decir que la museografía contextual no se basa únicamente en la recreación, sino que existe otro recurso expositivo igualmente importante, la recuperación o reconstrucción (Vaquero Argüelles, 2013: 135), pudiendo coexistir ambos y que no detallaremos, puesto que no fue empleado por Vega Inclán ${ }^{4}$. Los espacios domésticos de las casas museo vegainclanianas forman parte de un orden simbólico mediante el cual su uso como signo va más allá de ser percibidos por los sentidos. Como señala Poulot, la institución museal aparece en nuestra época como un hito para ilustrar la historia de las ideas (Poulot, 1986: 97-98). La Casa del Greco se convierte en una suerte de semióforo, principio que el marqués aplicará a otros proyectos museísticos como la Casa de Cervantes en Valladolid y el Museo Romántico de Madrid, ilustrando el desarrollo de la imagen de España y de su legado artístico a principios del siglo XX. Vega Inclán se convierte en un museólogo que hace de la relación hombre/sociedad/patrimonio el centro de sus proyectos culturales.

4 La recreación y la recuperación o reconstrucción son las principales prácticas museales empleadas en las casas museo y constituyen el objeto de estudio de la Tesis Doctoral de de la autora, "Las casas museo en España. Análisis de una Tipología Museística Singular", dirigida por la Catedrática de Historia del Arte de la Universidad de Murcia, Dra.Concepción de la Peña Velasco. 
¿Qué forma turística tenía de ver una casa museo? Don Benigno, con sus tres casas museo, consagra la creación de unos atributos turísticos ligados a Toledo, a Valladolid y a Madrid, estos últimos sin el potencial del primero, que funcionó como un verdadero paisaje semiológico. La Casa y el Museo del Greco se constituyen en el núcleo de un futuro negocio, por lo que fue el momento de explorar nuevas vías viajando a Estados Unidos consciente de que su nuevo producto poseía la cualidad específica de ser ofertado. En este sentido Moreno Garrido define a don Benigno como "el primer empresario turístico-cultural de España" (Moreno Garrido, 2005: 34) y a la Casa Museo del Greco como "el primer negocio turístico-cultural privado de la España moderna" (Moreno Garrido, 2004: 207), reflejando cómo tres años después de su inauguración aumentó enormemente el número de visitantes. Del millar de visitantes en 1909 se pasó a 40.000 en 1913. Estamos ante la primera casa museo turística, ante la materialización oficial a gran escala del turismo español y, como tal, quedará incorporada en cualquier circuito de lugares visitables. La nación se venderá como un gran museo de arte, con Toledo como punto de partida. La atención prestada a los Estados Unidos como una potencial fuente de turistas se justifica dentro de su estrategia de promover las relaciones internacionales fomentando los vínculos entre América y España. Kagan señala que cuando Vega Inclán pensaba en los turistas tenía en mente más a los americanos que a los europeos, no solamente los de la América hispana, sino también aquellos de Estados Unidos. El marqués entendió la afluencia de visitantes extranjeros y peninsulares como una "gran empresa nacional, fuente de riqueza pública y privada y un medio para fortalecer los lazos entre países", en clara relación con el pensamiento regeneracionista, dentro de un novedoso concepto del turismo que englobaba los monumentos, los museos, los paisajes y los parques naturales, y que actuaba en infraestructuras viarias, en la creación de redes de alojamientos y en la divulgación de las tradiciones (tipos humanos, folklore). Sus casas museo recrean el espíritu de una época a través de destacadas figuras nacionales, legitimando una nueva autenticidad. De esta manera el interés turístico se suma a las estrategias de patrimonialización más comunes, como la recuperación nostálgica, la reivindicación de la identidad nacional o la alegoría romántica.

El deseo de evocar el espíritu de una época en la que el Greco y, más tarde, Cervantes, habían vivido y trabajado es paralelo al de Archer Milton Huntington con su creación de la Hispanic Society of America en 1904, quien participó activamente en los proyectos de su amigo Vega Inclán, como en las casas del Greco y Cervantes, y con su Museo Español, "Un museo [...] que ha de condensar el alma de España en contenidos, a través de obras de la mano y del espíritu. No ha de ser un montón de objetos acumulados al buen tuntún hasta que todo ello parezca una asamblea artística [...]. Lo que quiero es ofrecer el compendio de una raza" (Codding, 2000). Tanto Vega Inclán como Huntington construyen una imagen del ser español más allá de la contraposición entre lo español y lo foráneo ofreciendo la imagen de una España plural y diversa. Pero era inevitable que cayeran en tipismos en cuanto tenían de peculiares o singulares las tradiciones españolas, como auténticas expresiones del espíritu del pueblo. Y en este sentido se acercan más a los planteamientos noventayochistas que reivindicaban una realidad nacional diferenciada y orgullosa de su casticismo. La relación entre ambos personajes es decisiva para comprender el sentido de las empresas culturales de Vega Inclán. Toledo, Valladolid y Madrid tenían sus propios mitos castizos que había que potenciar en el extranjero. El marqués realiza un trayecto inverso al de Huntington: 
viajaría personalmente a diversos lugares de la geografía americana para conocer de primera mano la impronta de lo español. Lavín rastrea su periplo en Sudamérica desde 1885 hasta 1898; en Buenos Aires en 1889; en Málaga, Madrid y Marruecos en 1893; en Uruguay en 1895; en las Antillas y en Centroamérica, entre otros (Lavín, 2016: 362-363) y destaca de manera significativa el viaje que realice en 1913: "uno de sus viajes más interesantes y apenas estudiados, la visita oficial a los Estados Unidos donde recorrerá todo el país de costa a costa y especialmente California desde la frontera de Méjico hasta el norte de San Francisco. Este viaje será determinante para la difusión de la imagen de España y de su arte y como plataforma de promoción de la recién abierta Casa del Greco y sus planes turísticos" (Lavín, 2016: 363). La fascinación por la tradición cultural española en Estados Unidos era evidente en las Exposiciones Internacionales; en la publicación de monografías de estudiosos norteamericanos, ingleses o alemanes sobre determinadas manifestaciones artísticas españolas, como por ejemplo los estudios de arte español realizados por Arthur Byne para Huntington, con quien tuvo una estrecha relación; en el nacimiento de la Hispanic Society of America, y en los viajes realizados por literatos, coleccionistas y marchantes (Martínez Ruiz, 2011: 51-52), entre los que se incluye el propio Vega Inclán, viajando de forma constante al extranjero.

\section{LA COMISARÍA REGIA DEL TURISMO Y LOS COMIENZOS DE LA MUSEO- GRAFÍA CONTEXTUAL EN ESPAÑA}

La creación de la Comisaría Regia del Turismo y Cultura Artística, a propuesta de Canalejas, entonces presidente del Consejo de Ministros, por Real Decreto de 19 de junio de 1911, se inserta en un contexto histórico marcado por las consecuencias del Desastre del 98 y por el deseo de Vega Inclán de conservar la riqueza artística, monumental y pintoresca de España, así como de favorecer la llegada de viajeros extranjeros. No nos vamos a detener en la labor desempeñada por la Comisaría Regia puesto que ha sido objeto de estudio por numerosos autores (Moreno Garrido, 2004, 2005 y 2007; Menéndez Robles, 2004 y 2006; Lavín, 2017, entre otros). Este organismo fija unas líneas de actuación del turismo que perdurarían hasta la actualidad. En su exposición de motivos mostraba una concepción del turismo directamente entroncada con la visión patrimonial de la Institución Libre de Enseñanza, que polarizó durante su existencia gran parte de las manifestaciones culturales de su tiempo. Ese amor por el arte y lo popular se materializaba en la casa madrileña de Juan Facundo Riaño y Emilia Gayangos, denominada "casa-museo"5 (López-Ocón, 2012: 65) y exquisitamente decorada en estilo inglés y granadino, que conocieron los institucionistas, donde su familia y él ejercieron de generosos anfitriones. Esa casa museo se alejaba de los excesos decorativos existentes en gran parte de las casas españolas, que fueron retratadas por Pérez Galdós en "La familia de León Roch" (1878).

Como Comisario Regio, consciente del potencial de sus proyectos museísticos 6 , comienza con Toledo y el Greco, y para ello recurre a la museografía contextual, lo que

5 Los detalles de la casa museo de Riaño se encuentran en la necrológica de Mariano Laliga y Alfaro, publicada en la Gaceta de Instrucción Pública, Madrid 30 de marzo de 1901, p. 111.

6 Un detalle significativo de la fuerza de los proyectos vegainclanianos lo prueba el hecho de que, por ejemplo, Bernaldo de Quirós, alumno de Francisco Giner y fundador y primer presidente de la Real Sociedad 
entonces constituía una novedad en España. El Greco necesitaba un inmueble a la altura de una ciudad histórica símbolo de una grandeza perdida: Toledo, como después lo serán Cervantes y Larra, otros mitos para la promoción turística de estos años. La Casa del Greco se convierte en un acto de autoafirmación nacionalista a la par que sirve de propaganda de la labor cultural de la monarquía. Es la primera casa museo española y la protagonista en la política turística española del primer tercio del siglo XX que comenzaba a hacer su aparición. En su deseo de promoción turística de Toledo, Vega Inclán, actuando como anfitrión y guía, convertirá en costumbre las visitas de personalidades relevantes. Así, la Casa del Greco "se convirtió en espacio privado del fundador, un centro de reuniones y encuentro con numerosas personalidades y visitas oficiales; una plataforma de divulgación del Greco y de Toledo, de la que se pueden encontrar numerosos testimonios en la prensa de la época. Las imágenes del Marqués acompañando al rey Alfonso XIII, a la reina Victoria Eugenia, a presidentes, ministros o figuras como Einstein, reflejan la posición estratégica que disfrutó la Casa del Greco desde su apertura” (Ruiz Gómez, 2013:16).

La Casa del Greco es la primera manifestación de la museografía contextual en España (Figura 1).

\section{Figura 1}

CASA MORENO. ARCHIVO DE ARTE ESPAÑOL (1893-1953). TOLEDO. SALA DE LA CASA DEL GRECO, DENOMINADA “ORATORIO" EN EL MONTAJE ORIGINAL DE VEGA INCLÁN. INV.00375_C

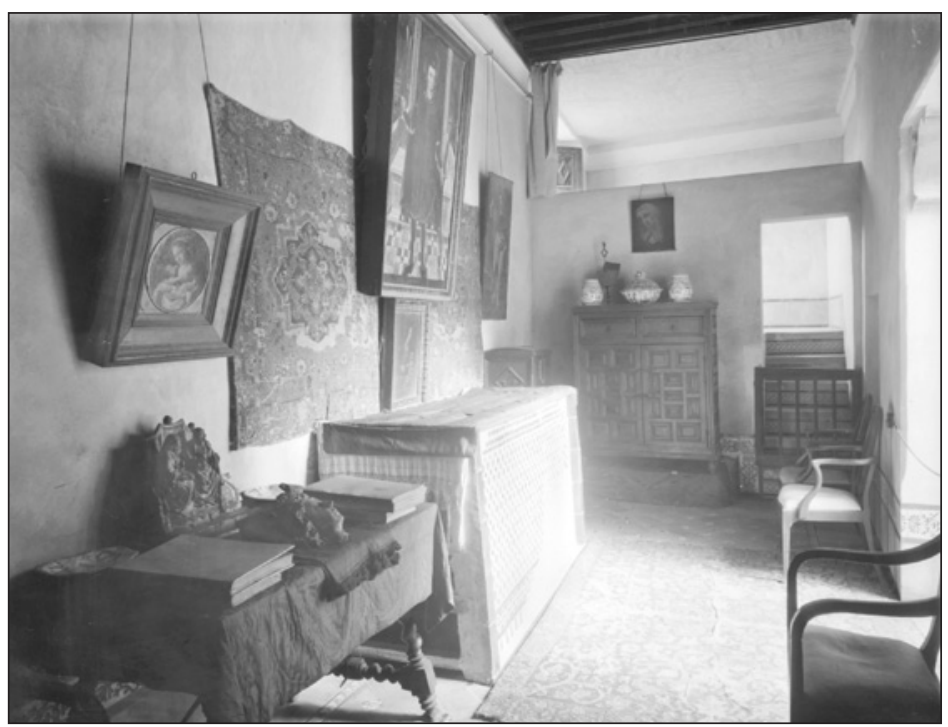

Fuente: Instituto del Patrimonio Cultural de España, Ministerio de Educación, Cultura y Deporte.

Española de Alpinismo Peñalara, contemplara la posibilidad de que Vega Inclán le ayudase a hacer de la cartuja del Paular "la Casa de Juan Ruiz, el arcipreste de Hita, nuestro más remoto guadarramista" (Bernaldo de Quirós, 1918: 309), de la misma manera que se haría con las casas del Greco y de Cervantes. 
Esta museografía contextual se caracteriza por ser el contexto la unidad expositiva, el entorno en el que se considera un hecho ${ }^{7}$. El contexto está determinado por la función doméstica de la casa, que es uno de los rasgos distintivos de una casa museo. Es un recurso expositivo que implica al visitante en una atmósfera única, que no es otra que el espacio habitacional y doméstico, la unidad doméstica, el ambiente en el que se desarrolló una vida generando experiencias que escapan a las características habitualmente asignadas al museo. De ahí que autores como Lavín empleen el concepto "museo de ambiente", que apela a la exhibición de los objetos en su espacio doméstico. El término "ambiente" tiene unas connotaciones más restrictivas que el de "contexto" porque no implica al edificio y a su entorno, sino únicamente al espacio doméstico. Cuando existen casas museo cuya condición viene subrayada por su vínculo con el inmueble y su entorno (jardines, parques, huertos, entre otros). "Ambiente” implica, además, un acotamiento de la museografía de una casa museo hacia la recreación, en la línea de la museografía de las salas de época o period rooms. El ambiente es una recreación del espacio doméstico. Desde este punto de vista, ¿dónde queda la recuperación o la reconstrucción? Por ello preferimos emplear el término de casa museo en vez de museo de ambiente, ampliando su significado conceptual y sus diferentes montajes expositivos. La casa museo es una tipología museística que goza de reconocimiento institucional desde 1997 y su museografía no se basa únicamente en la recreación, sino que extiende sus límites hacia la recuperación y la reconstrucción, que no son necesariamente excluyentes, y hacia su entorno, que va más allá del espacio doméstico. Lo que explica la singularidad, la base común y las representaciones sociales compartidas en una casa museo. El contexto es igual que las experiencias humanas, en cada momento y en cada situación las experiencias definen la manera en que vemos la situación actual.

Una museografía contextual controla la manera en la que se entiende y se produce el discurso expositivo y permite una adaptación de dicho discurso o de sus interpretaciones a la situación comunicativa según su relevancia. Constituye una interfaz entre el discurso y la sociedad, entre lo personal y lo social. Dentro de esta museografía distinguimos entre el contexto primario y el contexto museológico. El contexto primario es el espacio doméstico original y es precisamente el más difícil de conservar, porque en la vida cotidiana hay un trasiego incesante de cambio de objetos, de uso de las habitaciones o de su disposición interna. Por el contrario, el contexto museológico es el espacio doméstico determinado por el profesional de museos, es la unidad habitacional musealizada, implicando cierto desprendimiento de la realidad y, en consecuencia, es una forma de sustitución de la realidad de la que se supone que debía dar testimonio (Desvallées, 1998) ¿Estamos ante una fantasía o ante una apropiación del pasado? ¿Potenciamos el hecho histórico o lo estético? El contexto representaría la realidad, estando fuertemente anclado en referencias de situaciones del mundo real (Montpetit, 1996) porque los espacios domésticos constituyen lugares reconocibles para el visitante: el comedor, el salón, el dormitorio, etc. o

7 Gutiérrez Usillos emplea el término "museología contextual” en el ámbito de la documentación museística para referirse a la ampliación de la dimensión tangible del objeto hacia los significados que el bien genera. Se pregunta si en determinados museos sería necesario llegar a contextualizar el objeto. En las casas museo es una premisa básica ligada a su razón de ser. Véase Gutiérrez Usillos, 2010: pp. 59-99. 
los objetos que forman parte de estas habitaciones. Su potenciación supone una ruptura con la tradición formalista que imperaba desde el siglo XVIII y que valoraba exclusivamente el arte como objeto artístico sin importar que era fruto de un período histórico.

La importancia del contexto ya fue intuida desde mediados del siglo XIX a través del empleo de period rooms en los museos de artes decorativas de los países anglosajones, que entendieron que para el visitante era más comprensible la contemplación de los objetos en su atmósfera porque incentivaba su comprensión histórica y cultural. De hecho, en los últimos años instituciones como el Victoria \& Albert Museum de Londres, conscientes del potencial de estos conjuntos decorativos, han abierto una nueva vía en la didáctica del patrimonio por su capacidad evocadora. También se fomentaba el contexto con la presentación de conjuntos de objetos en los propios escaparates de las tiendas de venta de bienes de lujo de numerosas ciudades europeas y americanas (Harris, 1978). Un ejemplo se encuentra en la galería de arte parisina del marchante alemán Siegfried Bing (1838-1905), abierta en 1895 y denominada Maison de l'Art Nouveau, cuyos objetos se exponían en interiores domésticos construidos por él mismo, a los que llamó salones. Esta forma de exponer la había trasladado a los salones dentro de la sección del arte industrial francés, en el marco de la Exposición Internacional de las Artes Decorativas Modernas de Turín de 1902. El período histórico también era favorable, puesto que había un deseo de educar y concienciar al público de los valores de la propia cultura. Y esta idea se conseguía mejor mediante la representación de una época o estilo que a través de un objeto aislado. La obra no se entiende por sí sola, sino en su contexto. Y, en efecto, aunque se encuentra determinada por el medio, es la causa del medio. Lo importante es la constatación de que el aislamiento de la obra no sirve para explicarla, sino su época ${ }^{8}$. La historia cultural se mostraba más eficazmente por períodos y por estilos, más que por materiales y técnicas. Precisamente el estudio de estos procesos históricos constituyó una de las principales preocupaciones de la historia de la cultura, que Burke periodiza entre 1800 y 1950 (Burke, 2006) más allá de la tradicional tarea del historiador de basarse en documentos oficiales. El contexto histórico en el que se potenciaban estas escenografías era favorable a las ideas desarrolladas por Taine: el objetivo básico del historiador es la reconstrucción del medio. El estilo queda subordinado a las escuelas nacionales o, como señalaba el propio Taine, las obras "ordenadas por familias en los museos y bibliotecas" (Taine, 1922: 22-23). No se valoraba tanto el aspecto formal como el histórico o cultural, que adquiere su máxima expresión en las casas museo. Vega Inclán era consciente de la necesidad de acondicionar unos espacios cargados de contenido que pretendían resumir toda una cultura o toda una época. Lo que supone una ruptura con la taxonomía tradicional presente en los museos de agrupar los objetos por materiales, por estilos, por cronologías o etapas históricas, por escuelas, para hacerlo en función de un período concreto en un espacio doméstico acorde.

8 Esta idea fue reiterada por Venturi "Con razón considera Taine que la obra de arte no es algo aislado, sino que, para comprenderla es preciso relacionarla con las otras obras del mismo artista, con la escuela o grupo al que el artista pertenece y con el mundo que le rodea y cuyo gusto está en consonancia con el suyo". Venturi, 1982: 218. 
Las casas históricas, antes de su conversión en museos, reflejaban una museografía contextual que creaba espacios domésticos concretos, sin pensar en su finalidad museística. En 1907 se admiraban las que captaban el espíritu de una época y por ello se aspiraba a lograr lo mismo dentro de los museos (Watts, 1908: 159). El expolio que sufrió el patrimonio histórico español durante los siglos XIX y XX (Fernández Pardo, 2007 y 2014; Socias Batet y Gkozgkou, 2012; Pérez Mulet y Socias Batet, 2011; Merino de Cáceres y Martínez Ruiz, 2012) nos ha privado de conocer gran parte de estos interiores históricos, en los que los objetos tenían una ubicación determinada, un significado concreto y una relación funcional, simbólica o estética con las restantes piezas dentro del mismo espacio doméstico, sin olvidar al propio inmueble y a su entorno. En 1872 Riaño nos daba una descripción demoledora: "a la destrucción causada por los franceses es preciso añadir la negligencia de los propios españoles para preservar los objetos artísticos coleccionados por sus antepasados. La nobleza española ha ido vendiendo gradualmente sus joyas, su plata y sus muebles antiguos, y luego los ha sustituido por cosas modernas, de manera que hay pocas casas históricas españolas en las que haya quedado algo importante" (Riaño, $1872, \mathrm{XX}$ ). No hay que olvidar que todavía a principios del siglo XX hay publicaciones como la de Byne y Stapley ("Spanish Interiors and Furniture”, 1921-2) que presentan los objetos en un contexto aparentemente original o las exposiciones monográficas de arte español organizadas por la Sociedad Española de Amigos del Arte, cuya museografía era similar a la de las casas de subastas americanas, con catálogos que servían para publicitar la venta (Lavín, 2016: 365-367).

La museografía contextual no siempre ha gozado de predicamento en Europa, a diferencia de lo que sucede en el mundo anglosajón. En realidad, su historia ha sido una suerte de controversia, puesto que entre los propios profesionales de museos existen posturas divergentes sobre sus aciertos y sus desventajas. En este último aspecto el peso de la tradición francesa es más que palpable. Un ejemplo paradigmático se encuentra en la Conferencia Internacional de Madrid, celebrada entre el 28 de octubre y el 4 de noviembre de $1934^{9}$ y auspiciada por la Oficina Internacional de Museos de la Sociedad de Naciones, con sede en París. En concreto, una de sus Conferencias de Estudios que estaba dedicada al tema Architecture et Aménagement des Musées d'Art supuso un hito por la necesidad de reflexión del papel de los museos en la sociedad y dejó patente que las colecciones debían evitar una museografía acumulativa apostando por espacios neutros que favorecieran la visita, eliminando cualquier interferencia visual o recurso escenográfico añadido. Así, la tradicional densidad expositiva se irá abandonando paulatinamente a finales del siglo XIX, como en la Sala de la Reina Isabel II del Museo Nacional del Prado (Madrid), en favor de una "tendencia estética", tal y como se denominaría en 1948 en la primera Conferencia Bienal del ICOM, que aísla la obra, dejándola sin intermediarios entre ella y el espectador. En la Conferencia de Madrid de 1934 hay cierto rechazo a la museografía contextual, pero las casas museo debieron quedar al margen de las reflexiones museológicas en la defensa de una asepsia expositiva, puesto que no se puede justificar en una casa museo.

9 La Conferencia de Museos de 1934 ha sido objeto de revisión en el Congreso Internacional de Museografía celebrado en la Real Academia de Bellas Artes de San Fernando de Madrid del 21 al 23 de noviembre de 2016. 
La acumulación suele asociarse a la museografía de las casas museo ${ }^{10}$. En realidad es una distorsión derivada de la confluencia de dos factores. El primero es la influencia de los conjuntos decorativos de los palacios y residencias nobiliarias. Por ejemplo, se sabe que la aristocracia prusiana y berlinesa del siglo XIX disponía sus colecciones en "habitaciones de estilo". El segundo es el hecho de que algunas de las colecciones privadas de la aristocracia y de la nueva burguesía enriquecida, cuando pasan a ser propiedad del Estado, se quieren preservar en su contexto primario. Esta presentación hace que grandes museos presenten salas con multitud de objetos. Wilhem von Bode, inspirado por la disposición de los objetos de las habitaciones de época de la aristocracia, aplicó esta idea al Kaiser Friedrich Museum, inaugurado en 1897, con period rooms, para que pudieran ser admiradas por los estudiosos y por el público en general, ideas que fueron pioneras en su tiempo. Asimismo, las publicaciones del momento recogen ejemplos de museos cuyas paredes se encuentran suntuosamente revestidas, destacando la de Theópile Gautier ("Guide de 1'amateur au musée du Louvre”, 1867) o la de Samuel F. B. Morse ("Descriptive Catalogue of the Pictures from the Most Celebrated Masters, Copied into the "Gallery of the Louvre", 1833). La acumulación no siempre era sinónimo de desorden, sino que había criterios de simetría en las agrupaciones de obras, como puede verse en las pinturas del siglo XIX de la Stallburg-Galerie en Viena o del interior de la Grande Galerie del Louvre.

El empleo de la museografía contextual es una realidad patente en los museos, tanto en exposiciones temporales como permanentes. El recubrimiento con tejido es casi una constante en numerosos museos europeos y norteamericanos. En España recordemos cómo estaban en los años ochenta del siglo XX las salas flamencas del siglo XVII o las de Goya en el Museo Nacional del Prado. Numerosos museos incluyen en su exposición permanente ejemplos de museografía contextual (Museo Nacional de Artes Decorativas de Madrid, Museo Nacional de Cerámica y de las Artes Suntuarias "González Martí" de Valencia, entre otros). En algunas exposiciones temporales se emplean colores de tonalidades intensas en las paredes (y que incluso varían en cada sala), se recurre a la iluminación natural o se colocan objetos exentos en el centro de las salas o adosados a las paredes, en lo que constituye una suerte de retorno al pasado (Harris, 2007). No hay que olvidar los actuales eventos de arte contemporáneo centrados en las bienales y documenta, que incluyen espacios domésticos. Por ejemplo, en la Documenta IX de Kassel Ilya Kabakov, con su Die Toilette (1992), recreó un interior híbrido que era a la vez un apartamento ruso de dos habitaciones y un baño público. O la exposición de Jan Hoet en Gante, Chambres d'Amis (1986), en la que invitaba a artistas a crear obras para las casas de 50 coleccionistas privados. La fascinación por esta museografía contextual también se hace patente en muchos artistas de los siglos XX y XXI, que interpretan de manera personal un espacio doméstico convertido en una Wunderkammern (Pérez Mateo y Marín Torres, 2006), como las diferentes Merzbau de Kurt Schwitters. Incluso

10 Cuando hay casas museo que carecen de objetos. Un caso paradigmático es Can Trincheria (Olot, Gerona), donde no hay bienes muebles vinculados a la casa, sino que es un inmueble que explica la historia de la familia y los procesos de restauración que en ella se han llevado a cabo. En este sentido, el vacío objetual potencia la contemplación del espacio cultural y emocional del propietario. 
la musealización de yacimientos arqueológicos, con resultados muy desiguales, se aproxima en ocasiones a escenarios de películas de peplum italiano de los años sesenta y setenta. Pero abre una vía en el conocimiento de las formas de vida de la Antigüedad con independencia de su mayor o menor rigor histórico ${ }^{11}$.

En España, la museografía contextual tiene su punto de partida en la Casa del Greco. Visitada por el público, tendrá una gran influencia en el sur de Estados Unidos, especialmente en su arquitectura, entre 1895 y 1930, destacando las figuras de los arquitectos George Washington Smith (1876-1930) y Addison Cairns Mizner (1872-1933). Este gusto por lo hispano, extendido también a la creación de espacios domésticos, se conoce como Spanish Revival Style o "Spanish Colonial Revival" (Gebhard, 1967) y es uno de los capítulos más interesantes de la influencia de lo español en América12. Surge por el deseo de conservar y fomentar la producción artística nacional y por mostrar las formas de vida americanas del pasado, especialmente de la época colonial porque recordaba el encuentro entre el Viejo y el Nuevo Mundo, justificando así el nacimiento y la identidad de las nuevas naciones (Bergeron, 2012: 67). Eventos como la Exposición HudsonFulton de 1909, potenciaron a los pioneros colonizadores y a lo cotidiano, situando a los objetos domésticos al mismo nivel que las grandes obras maestras. Frente a los museos europeos centrados en las obras maestras, los americanos de historia se centran en la cultura popular y la vida cotidiana (Mairesse, 2009; Davallon, 2009). Ese apego a la historia de lo cotidiano ${ }^{13}$ legitima la moda de la recreación de los interiores domésticos, donde lo español ocupaba un lugar destacado. No hay que olvidar la exposición ByneStapley Expedition que organizó la Hispanic Society en 1918 con 1.200 fotografías sobre arte y arquitectura españolas (Merino de Cáceres, 2011: 251). La Casa del Greco no será ajena a esa fiebre por lo español, siendo reproducida total o parcialmente en algunos de estos edificios o mansiones (Menéndez Robles, 2014:107-108) vistas como “museos domésticos" (Gómez Martínez, 2006: 186), con independencia del mayor o menor rigor histórico, denominándose algunas de ellas "villas españolas" ${ }^{14}$. Este historicismo se convertiría en paradigma de la España imperial (López Trujillo, 2006; Kagan, 2010; Suárez-Zuloaga y Kagan, 2010), definido como un "período en el que los magnates del capitalismo se vieron a sí mismos como nuevos Medici respecto al patrocinio artístico" (Gómez Martínez, 2006: 64). En este contexto Vega Inclán era consciente de explotar

11 Ejemplos de reconstrucciones de villas en España son la Domus de la Fortuna (Cartagena), la Domus de los Grifos de Complutum (Alcalá de Henares) o la Domus romana de Julióbriga (Retortillo, Campoo de Enmedio). Un camino que hay que destacar en estas reconstrucciones es el de la aplicación de nuevas tecnologías, infografía y realidad aumentada, en la línea de algunos parques arqueológicos anglosajones como el Jorvik de York UK (http://jorvik-viking-centre.co.uk/) y el yacimiento colonial norteamericano de Williamsburg (http://www. history.org/index.cfm) [consulta 22/01/2014]. Agradezco las apreciaciones de Jesús Bermejo Tirado, Doctor en Historia por la Universidad Complutense de Madrid.

12 Una de las casas que ejerció mayor influencia de acuerdo con el Spanish Revival Style fue la mansión de George Fox Steedman, conocida como "La Casa del Herrero", construida por George Washington Smith, que los Byne contribuyeron a decorar. Véase Merino de Cáceres, 2011: 251-253; Gebhard, 2005; Mcmillian y Gainer, 2002.

13 Tuvo una de sus máximas expresiones en la frase acuñada por Bushnell en 1864 de "The Age of Homespun". Véase Bushnell, 1864 y Thatcher, 2001.

14 También denominadas Spanish Palm Beach Style o Mizner's Spanish Style. Véase Merino de Cáceres, 2011: 251-255 
la Casa del Greco como un recurso turístico ya que en Estados Unidos lo cotidiano, lo inmediato e incluso lo funcional era realmente lo que daba razón de ser a los museos $\mathrm{y}$, muy especialmente, a las casas museo, instituciones que se prestaban como pocas a reforzar la diferencia y la singularidad de lo propio. Lo aplicará posteriormente a la Casa de Cervantes (1916) y al Museo Romántico (1924), que estaban bajo su gestión directa a través de Patronatos y luego de las Fundaciones homónimas, que las dirigirán cuando él desaparezca, puesto que en su testamento las declaraba herederas universales de sus bienes.

\section{VEGA INCLÁN Y EL TURISMO VISIONARIO DE LAS CASAS MUSEO ¿UN NEGOCIO TURÍSTICO- CULTURAL?}

En este apartado definimos los principales rasgos que permiten calificar de "visionaria" la concepción turística de las casas museo ideadas por Vega Inclán. En primer lugar, porque plantean una museografía basada en la ficción, creando un mundo imaginario por oposición al mundo real, dialéctica que sigue siendo motivo de controversia entre los profesionales de los museos. Es conocida la correspondencia mantenida entre Cossío, el inspirador intelectual de la Casa del Greco, y Vega Inclán, su creador, a propósito de la autenticidad o la invención de la Casa del Greco (Menéndez Robles, 2009; Lavín, 2017). Vega Inclán se decanta por crear una ficción, consciente de que la representación de la realidad histórica es una quimera. Esa aspiración por querer preservar lo auténtico ha sido una constante en la historia de nuestro patrimonio: la idea que tenemos de un objeto o monumento suscita la fantasía de que ese era su aspecto en el pasado. Muchos otros lo saben pero el deseo de creer hace que sea posible la ilusión de la verdad. Recordemos la Casa Natal de Velázquez en Sevilla, el Museo Casa de Dulcinea del Toboso (Toledo) o la Casa de Viriato en Torrefrades (Zamora), entre otros ejemplos. Es la museología anglosajona la que adopta con mayor naturalidad este tipo de recreaciones especialmente a través de las period rooms (Gómez Martínez, 2006; Rodríguez Marco, 2013) ¿Cómo se puede recrear el pasado?, ¿hasta qué punto?, ¿es productivo recrearlo?, ¿se pueden presentar diferentes modos y/o niveles de recreación histórica? Si la recreación nos acerca a la "realidad" de la historia ¿cuál es el modo más efectivo de hacerla comprensible? Este es uno de los mayores desafíos a los que se enfrenta el profesional de museos: trasladar el contexto primario de una casa al contexto museológico de una casa museo partiendo de la premisa de que la realidad es una ficción. La recreación parece ser la única alternativa posible. ¿Es este proceso sostenible en el tiempo?, ¿presenta aportes cualitativos desde el punto de vista de la recuperación de la identidad del lugar y del personaje?

Don Benigno sabía que la recreación de los espacios de la Casa del Greco, que mantuvo para su uso privado hasta su fallecimiento, no se correspondía a la realidad histórica, sino que se justificaría por la representación del espíritu de una época concreta. Reconstruir físicamente el pasado suponía una metáfora de sus deseos, dándole un significado concreto entre los muchos posibles. La casa grequiana encarna la representación de la historia en distintos grados de simulación. La utopía se realiza al menos como imagen 
volumétrica, mientras que la realidad se desvanece dando paso al simulacro. El recurso a la ficción, reinventando la cotidianeidad de un personaje, daría comienzo a un debate sobre la «autenticidad» del elemento patrimonial, la Casa del Greco, que llega hasta nuestros días culminando con la destrucción simbólica del mito de la casa, una fícción verosímil, a medida que hemos ido convirtiendo las ficciones en realidades y las realidades se acaban transformando. La "autenticidad" tiene que ver con el carácter simbólico de ese patrimonio. En este sentido se puede definir el turismo vegainclaniano como un mundo de ficciones, de imágenes que en la actualidad nos llevaría a preguntarnos dónde comienza la realidad y dónde el espectáculo. En Valladolid sigue el mismo proceso que en Toledo: rehabilita el inmueble identificado como la casa que habitara Cervantes, cuyos interiores serán recreados por Laredo y Traver respetando la idea de Pérez Mínguez ${ }^{15}$ (Figura 2), para entregarla al Estado una vez rehabilitado.

\section{Figura 2 \\ OTTO WUNDERLICH. FOTOGRAFÍA TOMADA ENTRE 1928 Y 1936. VALLADOLID. VISTA DE UNA HABITACIÓN DE LA CASA DE CERVANTES. INV. WUN-07444.}

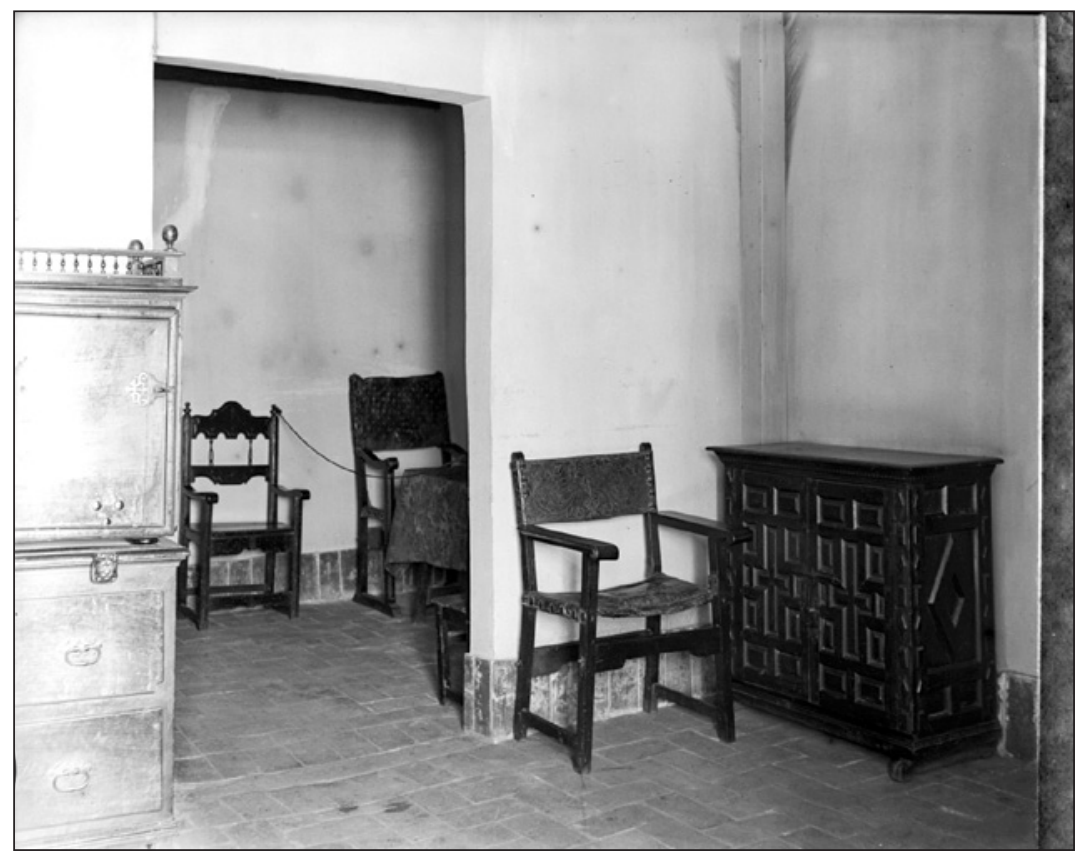

Fuente: Instituto del Patrimonio Cultural de España, Ministerio de Educación, Cultura y Deporte.

15 Para Doménech la poética histórica de Pérez Mínguez ha sido sustituida por la ideología histórica de Vega Inclán. Doménech, 2007: 184. 
Esta casa no llegó a abrirse como museo en vida de Vega Inclán. Únicamente fue visitada por miembros de la familia Real. A diferencia de la Casa del Greco, Vega Inclán estaba ante el verdadero inmueble en el que habitó Cervantes entre 1603 y 1606 (Pollán Palomo, 2016). Aun existiendo un inmueble auténtico no quedaban vestigios originales de las habitaciones ni de sus objetos, pero decide su consagración a otro mito. El marqués se enfrenta a una segunda recreación, vinculada a Miguel de Cervantes y a una ciudad que había sido sede de la monarquía hispana, Valladolid, aunque ésta no suministrase con la misma intensidad los arquetipos que suscitaba Toledo ya desde el siglo XIX. En 1916 el Estado acepta la donación que el rey hace de la casa señalando que "pretende dar vida espiritual a la institución cervantina para que sea objeto de peregrinación por parte de cuantos se acerquen a ella a rendir un homenaje a Cervantes, al habla castellana y a España" (Menéndez Robles, 2009: 177). En el caso del Museo Romántico quedaba el inmueble, que había estado habitado por los condes de la Puebla del Maestre en la época romántica, un período histórico que Vega Inclán quería revalorizar, con Larra a la cabeza. Para ello planteó una recreación de espacios domésticos vinculados al Romanticismo (FIG. 3), creando un "Museo de vida" (Ortega y Gasset, 1922) cuyo espíritu recogen las crónicas de la época: “Casa deshabitada en apariencia; pero en la cual toda una familia vive su realidad espiritual. ¡Prodigiosa realidad .Ninguna tan cierta como esta de lo inmaterial, de lo que solo era espíritu. Si de pronto el fantasma del pasado se hiciera imagen tangible, no experimentaríamos la vaga emoción que ahora nos prende cuando empezamos a recorrer esta casa sin personajes [...] ¿Para qué mas? ¿Qué importan los personajes? Está aquí cuanto les rodeó sellado con la marca espiritual del siglo romántico. Aunque no hablemos con ellos, el diálogo con las habitaciones será formidable. Los retratos desde sus cuadros nos mirarán; y los sofás nos invitarán a sentarnos, con el mudo ademán de sus brazos" ${ }^{16}$. El marqués se adelanta a la revalorización de una época histórica, el siglo XIX español, que fue denostada en su tiempo. Los objetos expuestos en él son manipulados simbólicamente al relacionarlos con una historia que queda legitimada por esos mismos objetos (Torres González, 2013a). El Museo Romántico, ahora Museo Nacional del Romanticismo ${ }^{17}$ (Torres González, 2006, 2008, 2009, 2010, 2009-2010, 2013c), fue la sede de la Comisaría Regia de Turismo ${ }^{18}$, a donde se trasladó desde la madrileña calle Sacramento, número 5. Es, además, la sede del Archivo Vega Inclán, con fondos documentales de valor incalculable que nos permiten conocer datos relativos a su actividad profesional y de mecenazgo, y a su vida pública y privada.

16 Castellón, 1930. Citado por Torres González, 2013b: 236.

17 Por Real Decreto 1827/2009, de 27 de noviembre, se otorga el carácter de museo nacional al Museo Romántico, se modifica su denominación por la de Museo Nacional del Romanticismo y se regulan sus fines y organización.

18 "La primera sede de la Comisaría Regia fue un despacho en el Palacio de las Salesas Reales, donde se encontraban las dependencias de la Presidencia del Consejo de Ministros pero, tras el incendio de este inmueble, pasó al domicilio particular del Marqués de la Vega Inclán, en la plaza de los Afligidos. Posteriormente se trasladó a calle Sacramento 5 y, finalmente, en 1921, a calle San Mateo 13, donde poco después se instalaría el Museo". Cabanillas García, 2012: 3. 


\section{Figura 3 \\ HAUSER Y MENET. 1924. MADRID. COMEDOR CON CERÁMICA ESPAÑOLA DEL MUSEO ROMÁNTICO}

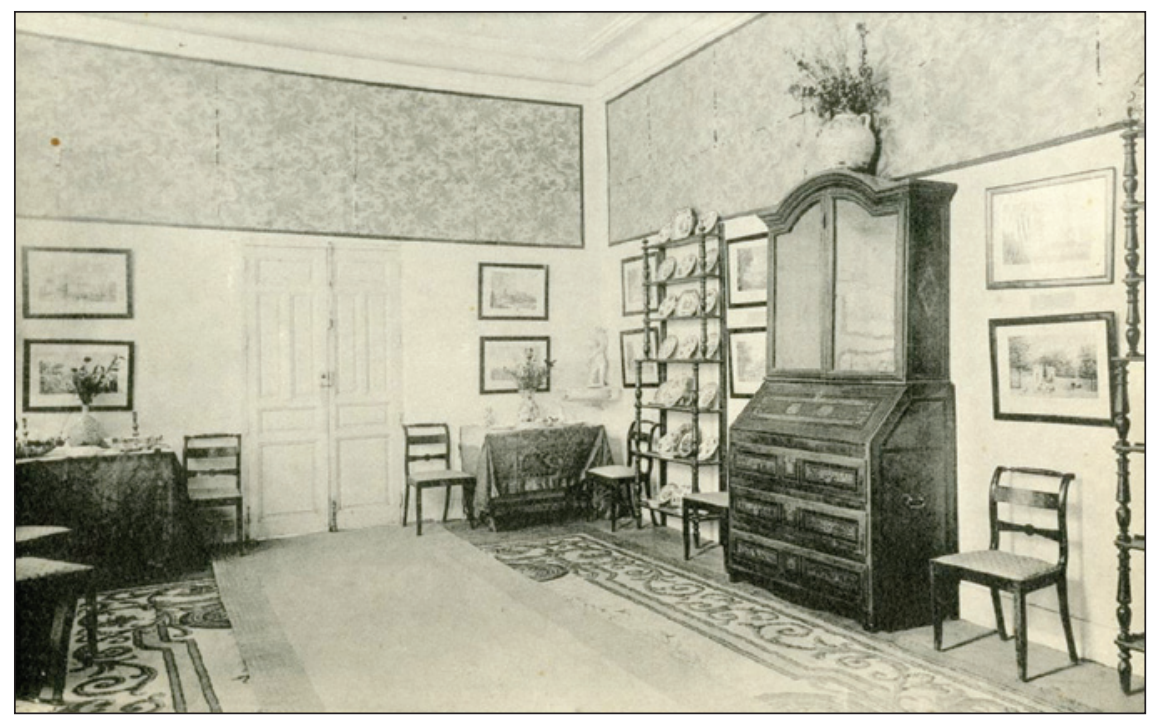

Fuente: Museo del Romanticismo. Ministerio de Educación, Cultura y Deporte.

Un segundo elemento que caracteriza a las casas museo vegainclanianas es el de ser construcciones culturales asociadas a la importancia de las memorias colectivas, de los mitos, de los símbolos. En efecto, el Greco es un héroe nacional en el sentido moderno del nacionalismo, pero ¿vinculado a Toledo o a España?, ¿un héroe toledano o español? El marqués nos da la respuesta cuando en 1928 señale que: "el punto central de nuestro movimiento de Turismo, debiendo considerar que Toledo es el centro geográfico de nuestro arte que debe atraer las peregrinaciones que a tierras españolas llegan, para que saturadas de formas e ideas que sugiere este Museo de todos los siglos, archivo de arte, de tradición y de historia, se propaguen por los ámbitos de nuestra Península y se dispersen por el mundo entero" (Vega Inclán, 1928: 227). La casa museo se presta, más que los restantes museos, a la heroización de un personaje. El marqués ensalza al Greco, Cervantes y Larra como unos nuevos héroes que suponen una alternativa a los iconos nacionales ya consagrados como Velázquez o Goya. Y su atractivo se potencia con su presentación en casas museo que exhiben su faceta pública y privada. ¿Cómo subrayar su ejemplaridad también en su vida cotidiana? El visitante se identifica con esa cotidianeidad puesto que come, duerme o satisface sus necesidades como nosotros. Las casas museo vegainclanianas deslocalizan la alta cultura generando una multiplicidad de culturas locales, dignas de ser protegidas como parte del patrimonio nacional en tanto que son referentes propios. Don Benigno forma parte de esa fiebre por lo nacionalista que se estaba produciendo desde finales del siglo XIX y que afectaba sobre todo a la interpretación del pasado (Storm, 2011). 
No es casual que los tres proyectos museísticos que ideó el marqués fueran casas museo. Ahí encontramos un tercer elemento que define su carácter visionario, ya que crea una nueva categoría museística: la casa museo, que a pesar de ser una tipología museística conocida fuera de nuestras fronteras, en España no ha ocupado un lugar relevante en los estudios museológicos ni patrimoniales. Es una realidad el desconocimiento de su existencia incluso entre los propios visitantes de museos. La revista Mouseion, pocos años después de su creación en 1927 por la Oficina Internacional de Museos, estableció en 1934 una división de casas históricas que podrían considerarse como casas museo, siendo la primera clasificación "oficial” de esta tipología museística. Sólo en 1997 le llegará su reconocimiento institucional, con la creación de DEMHIST, el Comité Internacional de Casas Históricas del ICOM, cuyo nombre es una abreviatura del término francés demeures historiques y que pretende convertirse en referencia para el desarrollo de estrategias de conservación y de intercambio, comunicación e información de casas históricas y casas museo, aumentando su visibilidad y potenciando el turismo en torno a estas instituciones. La casa museo era una tipología museística habitual en el siglo XIX, cuyo origen se puede encontrar en la institucionalización del Shakespeare's Birth Place, en Stratford. A mediados del siglo XIX la casa natal de Shakespeare contaba con guías en las que se informaba de la no autenticidad de los objetos expuestos. Aún así, es una de las casas museo más visitada del Reino Unido. Si nos remontamos más atrás en el tiempo recordaremos la visita a Kedleston Hall en 1794 de Samuel Johnson y James Boswell, guiados por la conservadora Mrs. Garnett con un inventario en la mano, uno de los primeros ejemplos de casas que desde el momento de su creación son visitadas por el público.

Un cuarto elemento es el poder del contexto, anticipandose Vega Inclán al valor de crear una atmósfera cercana, comprensible, manejable, que genera en el visitante una serie de experiencias que sólo serían posibles con esta museografía, potenciando el valor comunicativo del edificio, del objeto y del entorno, reemplazando al tradicional valor de culto atribuido al museo. Lo que enlaza con la museología alemana del siglo XIX, con Bode a la cabeza, al señalar que las period rooms, con su contextualización de objetos de la misma época y/o estilo, permiten la mejor comprensión de que el arte es fruto de un contexto histórico y que es diferente también en función de éste. Se reconocía implícitamente el valor semiótico de estos bienes, empleados como un vehículo de transmisión del pasado, como signos que ofrecen información al público, como una forma de rememoración, activando el pasado en el presente. Es un montaje que apela a la imaginación del espectador ofreciéndole la imagen de un tiempo pasado (Pérez Mateo, 2007). Se invitaba a la especulación, a imaginar las relaciones de los objetos con el espacio en el que se ubican. El misterio viene dado por la discontinuidad y desconexión del presente y por la emoción del descubrimiento de lo propio como si de un espejo se tratase. Con este tipo de conjuntos el visitante se convierte en un turista de la realidad del pasado. La importancia otorgada a la experiencia del visitante adquirió reconocimiento institucional en la "Carta Internacional sobre Turismo Cultural", adoptada por ICOMOS en 1999 resaltando la interacción dinámica entre turismo y patrimonio cultural. Además, la interpretación ambiental de este patrimonio se relaciona con el valor que los arquitectos otorgaban a la arquitectura y su entorno urbanístico y, sobre todo, 
con la orientación patrimonial y paisajística de la Institución Libre de Enseñanza, a la que el Marqués estaba próximo, así como con los miembros de la Generación del 9819, especialmente con Cossío, Manuel Gómez-Moreno o Elías Tormo. La idea moderna de paisaje y su patrimonialización como fuente de identidad se desarrolla en relación con la emergencia de los nacionalismos y los procesos de construcción social. Las casas museo vegainclanianas potencian la valoración de la ciudad como paisaje nacional y a ello contribuyeron las guías turísticas editadas por la Comisaría Regia que incluían las Casas del Greco y de Cervantes y el Museo Romántico. El Greco aparecerá dentro de la colección "El Arte en España”, una de las iniciativas editoriales más interesantes de la Comisaría, editada en Barcelona por Thomas. De pequeño formato, presentaba textos escritos en español, francés e inglés por personalidades ilustres que describían los principales artistas y monumentos españoles y estaba profusamente ilustrado. Moreno Garrido señala que su estética era deudora de unos libritos editados por el Touring Club Italiano y la sociedad Dante Alighieri, L'Italia monumentale (Moreno Garrido, 2012:240-241). Todas las publicaciones de la Comisaría se distribuyeron gratuitamente, pero en la actualidad son de difícil localización, conservándose gran parte de ellas en el Archivo Vega Inclán del Museo del Romanticismo.

La museografía contextual continúa en nuestros días bajo la forma del turismo experiencial (Prentice, 2001: 13). Este turismo, también denominado vivencial, considera fundamental la venta de experiencias, de historias para ser contadas y vividas. Esto tiene mucho de perfomance ya que es el espectador el que se identifica imaginativamente con los hechos o los personajes que conmemora la casa museo. La "autenticidad" es fundamental para que la experiencia turística sea memorable (Wang, 1999). Esta inmersión ha llevado a algunos autores a emplear el término de "museografía inmersiva", especialmente aplicado a los museos vinculados al ámbito de las ciencias de la naturaleza, cuando es también es un recurso expositivo empleado por las casas museo, que puede llevar al visitante a no distinguir entre la realidad y la ficción. Esta experiencia se traduciría en términos emocionales (fascinación, olvido de la rutina, evasión, entre otros) y de la que hay ejemplos elocuentes en la Casa Natal de Cervantes en Alcalá de Henares, el Museo Casa Cervantes en Valladolid o el Museo Casa Dulcinea del Toboso en Toledo (Jiménez Sanz y Urbina Álvarez, 2009; Serrano García, Sanz Ballesteros y Coso Marín, 2007; Fontes Blanco, 2016), entre otros.

Don Benigno recrea tres espacios domésticos vinculados a contextos culturales distintos (Renacimiento, Siglo de Oro y Romanticismo) y a personajes gloriosos de la cultura española (El Greco, Cervantes y Larra) en una suerte de "poética histórica" (Bann, 1984) en la que el objeto se apropia del pasado. Bann explicaba este deseo de reconstrucción como un producto de ideologización histórica, el cual ya era evidente a comienzos del siglo XIX. Vega Inclán convierte las casas museo en una serie de elementos patrimoniales de la ciudad, esencialmente vinculadas con un personaje. En este sentido resultan reveladoras las palabras de Santiago Camarasa en 1927: "Turismo español: Toledo; y turismo toledano: Greco (...). Porque si Toledo es la base del Turismo nacional, el Greco es la base del turismo toledano" (Camarasa, 1927: 11- 23). La valoración simbólica y patrimonial de

19 Aspecto señalado por Torres González. Vega Inclán está muy próximo en sus preferencias artísticas a los noventayochistas. Torres González, 1999b. 
las casas museo se realizó en clave nacionalista, pero también son lugares de memoria al servicio de los intereses y objetivos de las élites, en este caso, Vega Inclán, un museólogo que se anticipará al potencial turístico de las casas museo.

\section{BIBLIOGRAFÍA}

ALMARCHA M.E; MARTÍNEZ BURGOS, P. y SAINZ, E. (Coords.) (2016): El Greco en su IV Centenario. Patrimonio Hispánico y diálogo intercultural. Castilla- La Mancha, Ediciones de la Universidad de Castilla-La Mancha.

ÁLVAREZ LOPERA, J.A. (1987): "Coleccionismo, intervención estatal y mecenazgo en España (1900-1936)", Fragmentos. Revista de Arte, n 11, pp. 33-47.

ÁLVAREZ LOPERA, J.A. (2008): "El Greco y sus obras entre dos exposiciones (19021909)", en El Greco, Toledo 1900. Madrid, Ministerio de Cultura, Caja Castilla-La Mancha, pp. 117-139.

BANN, S. (1984): The Clothing of Clio. A study on the representation of history in nineteenth-century Britain and France. Cambridge, Cambridge UP.

BERGERON, Y. (2012): “¿Museos a la deriva o continentes a la deriva: consecuencias de la crisis financiera para los museos de América del Norte", en Museos y turismo: expectativas y realidades. Bilbao, Servicio Editorial de la Universidad del País Vasco, pp. 61-83.

BERNALDO DE QUIRÓS, C. (1918): “Sobre el aprovechamiento del Paular”, Peñalara. Revista mensual de alpinismo, $\mathrm{n}^{\circ} 59$, p. 309.

BURKE, P. (2006): ¿Qué es la historia cultural?. Barcelona, Paidós.

BUSHNELL, H. (1864): "The Age of Homespun", en Work and Play; or Literary Varieties. New York, Charles Scribner, pp. 374-408.

CABANILLAS GARCÍA, M. (2012): "Introducción a la Comisaría Regia de turismo. La figura del Marqués de la Vega-Inclán como Comisario Regio". Disponible en http:// www.mecd.gob.es/mromanticismo/dms/museos/mromanticismo/actividades/exposiciones/historico/2014/articulo-comisaria-regia.pdf [consulta 08/02/2017].

CABALLERO GARCÍA, L. y LAVÍN BERDONCES, A.C. (2007): “Una exposición comunicativa para un museo de arte: El proyecto de exposición permanente del Museo del Greco", Museos.es. Revista de la Subdirección General de Museos Estatales, nº 3, pp. 64-83.

CAMARASA, S. (1927): El turismo en Toledo: estudio premiado. Toledo, Estudio Tipográfico de A. Medina.

CODDING, M.A. (2000): “The Soul of Spain in a Museum: Archer Milton Huntington's Vision of The Hispanic Society of America", en The Hispanic Society of America: Tesoros. Nueva York, The Hispanic Society of America, pp. 15-37.

CHOAY, F. (1992): L'Allégorie du patrimoine. Paris, Seuil.

CHOAY, F. (2009): Le patrimoine en questions. Anthologie pour un combat. Paris, Seuil.

DAVALLON, J. (2009): “Objets d'exposition: objets de mémoire, objets de patrimoine?”, en Mémoires de Mémoires. Étude de l'Exposition Inaugurale du Musée de la Civilisation. Québec, Presses de 1'Université Laval, pp. 141-158.

DESVALLÉES A. (1998): "Cent quarante termes muséologiques ou petit glossaire de l'exposition”, en Manuel de muséographie. Paris, Séguier- Option culture, pp. 205- 251. 
DESVALLÉES, A. y MAIRESSE, F (Dir.) (2011): Dictionnaire encyclopédique de muséologie. París, Armand Colin.

DOMÉNECH, J. (2007): "Vivir el pasado". Imaginación mito-poética en las casas-museo de El Greco y Cervantes", Anuario del Departamento de Historia y Teoría del Arte, $\mathrm{n}^{\circ} 19$, pp. 179-188.

FERNÁNDEZ PARDO, F. (2007): Dispersión y destrucción del patrimonio artístico español. Compilación histórica con índices (5 vols.). Madrid, Fundación Universitaria Española.

FERNÁNDEZ PARDO, F. (2014): Dispersión y destrucción del patrimonio artístico español. Compilación histórica con índices (vol. VI). Madrid, Fundación Universitaria Española.

FONTES BLANCO, F.L. (2016): "El Museo Casa de Dulcinea en El Toboso (Toledo). Su historia y sus últimas formulaciones museológicas y museográficas”, en Colecciones Cervantinas. Madrid, Ministerio de Educación, Cultura y Deporte, pp. 39-47.

GAYA NUÑO, J.A. (1958): La pintura española fuera de España. Madrid, Espasa Calpe.

GAYA NUÑO, J.A. (1964): La pintura europea perdida por España. De Van Eyck a Tiépolo. Madrid, Espasa Calpe.

GEBHARD, D. (1967): “The Spanish Colonial Revival in Southern California (18951930)", Journal of the Society of Architectural Historians, vol. 26, n 2, pp. 131-147.

GEBHARD, P. (2005): George Washington Smith. Architect of the Spanish Colonial Style. Utah, Layton.

GÓMEZ MARTÍNEZ, J. (2006): Dos Museologías. Las tradiciones anglosajona y mediterránea: diferencias y contactos. Gijón, Trea.

GUTIÉRREZ USILLOS, A. (2010): Museología y documentación. Criterios para la definición de un proyecto de documentación en museos. Gijón, Trea.

HARRIS, N. (1978): "Museums, Merchandising, and Popular Taste: The Struggle for Influence", en Material Culture and the Study of American Life. Nueva York, Norton, pp. $140-174$.

HARRIS, J. (2007): Moving rooms: The trade in architectural salvages. New Haven and London, Yale University Press.

JIMÉNEZ SANZ, C. y URBINA ÁLVAREZ, A. (2009):”Museos de Lope de Vega y Cervantes. Dos casas museo de escritores de titularidad de la Comunidad de Madrid", Poliédrica Palabra, no 3, pp. 4-9.

KAGAN, R. (Ed.) (2002): Spain in America. The origins of Hispanism in the United States. Chicago, University of Illinois Press.

KAGAN, R. (2010): "The Spanish Craze in the United States: Cultural Entitlement and the Appropriation of Spain's Cultural Patrimony, ca. 1890-ca.1930", Revista Complutense de Historia de América, $\mathrm{n}^{\circ}$ 36, pp. 37-58.

KAGAN, R. (2013): "El Marqués de Vega-Inclán y el patrimonio artístico español. ¿Protector o expoliador?", en Nuevas contribuciones en torno al mundo del coleccionismo de arte hispánico. Gijón, Trea, pp. 193-203. 
LAVÍN BERDONCES, A.C. y CABALLERO GARCÍA, L. (2007a): "Plan Museológico del Museo del Greco, Toledo (España)", en Plan Museológico y Exposición Permanente en el Museo. Madrid, Ministerio de Cultura, pp. 83-114.

LAVÍN BERDONCES, A.C. y CABALLERO GARCÍA, L. (2007b): "Plan Museológico del Museo del Greco", en El Greco's Studio, proceedings of the International Symposium. Iraklion: Crete University Press, pp. 441-488.

LAVÍN BERDONCES, A.C. (2007c): "El Museo del Greco, memoria de un sueño", en Tesoros Ocultos, fondos selectos del Museo del Greco y del Archivo de la Nobleza. Madrid, Ministerio de Cultura, pp. 17-35.

LAVÍN BERDONCES, A.C. (2008): "La consagración del mito del Greco en Toledo: Vega Inclán, el Museo del Greco y el homenaje de 1914”, en El Greco, Toledo, 1900. Madrid, Ministerio de Cultura, Caja Castilla-La Mancha, pp. 171-209.

LAVÍN BERDONCES, A.C. (2009) "El Greco entre dos siglos, de la construcción de un pintor al nacimiento de un mito", en Domenikos Theotocopoulos 1900. El Greco. Madrid, Ed. Seacex y TF, pp. 21-52.

LAVÍN BERDONCES, A.C. (2013): "El Museo del Greco: la casa inexistente”, en Casas museo: museología y gestión. Actas de los Congresos sobre Casas Museo (2006, 2007, 2008). Museo Nacional del Romanticismo. Madrid, Ministerio de Educación, Cultura y Deporte, pp. 171-182.

LAVÍN BERDONCES, A.C. (2016): "El marqués de la Vega Inclán en el año del IV Centenario de la muerte del Greco. Una revisión crítica del personaje", en El Greco en su IV Centenario. Patrimonio Hispánico y diálogo intercultural. Castilla-La Mancha, Ediciones de la Universidad de Castilla-La Mancha, pp. 347-375.

LAVÍN BERDONCES, A.C. (2017). La creación de los museos de ambiente en España: La Casa y el Museo del Greco de Toledo. [Tesis] Universidad Complutense de Madrid.

LÓPEZ-OCÓN, L. (2012): "El papel de Juan Facundo Riaño como inductor del proyecto cultural del Catálogo Monumental de España”, en El Catálogo Monumental de España (19001961): Investigación, restauración y difusión. Madrid, Ministerio de Cultura, pp. 51-73.

LÓPEZ TRUJILLO, M.A. (2006): La lucha por los bienes culturales españoles (15001939). Gijón, Trea.

McMILLIAN, E.J. y GAINER, M. (2002): California Colonial: The Spanish and Rancho Revival Styles. Pennsylvania, Schiffer Publishing.

MAIRESSE, F. (2009): "Le traitement muséal de la mémoire québécoise. Un point de vue", en Mémoires de Mémoires. Étude de l'Exposition Inaugurale du Musée de la Civilisation. Québec, Presses de 1’Université Laval, pp. 249-262.

MARTÍNEZ RUIZ, M.J. (2011): "Raimundo y Luis Ruiz: pioneros del mercado de antigüedades españolas en EE.UU”, Berceo, n 161, pp. 49-87.

MENÉNDEZ ROBLES, M.L. (2000a): "La Casa de Cervantes en Valladolid y el Segundo Marqués de la Vega-Inclán”, en Ante el nuevo milenio. Raíces culturales, proyección $y$ actualidad del arte español: Actas del XIII congreso CEHA. Granada, Universidad de Granada, pp. 567-577.

MENÉNDEZ ROBLES, M.L. (2000b): "Sorolla, Benlliure y el II Marqués de la VegaInclán: interacciones amistosas y artísticas”, en Mariano Benlliure y Joaquín Sorolla, centenario de un homenaje. Valencia, Generalitat Valenciana, pp. 56-74. 
MENÉNDEZ ROBLES, M.L. (2004): Un mecenas de la España alfonsina: El II Marqués de la Vega- Inclán (1858-1942). [Tesis] UNED.

MENÉNDEZ ROBLES, M.L. (2006): El marqués de la Vega Inclán y los orígenes del turismo en España. Madrid, Ministerio de Industria, Turismo y Comercio.

MENÉNDEZ ROBLES, M.L. (2008): La huella del marqués de la Vega Inclán en Sevilla. Sevilla, Diputación.

MENÉNDEZ ROBLES, M.L. (2009): "Mecenazgo e implantación de las Casas-museo en España”, en Museos \& Mecenazgo. Nuevas aportaciones. Actas de las Jornadas Museos y Mecenazgo. Nuevas aportaciones. Madrid, Fundación Sorolla, Instituto de Humanidades de la Universidad Rey Juan Carlos, pp. 51-75. Disponible en http://hdl. handle.net/10115/2505 [consulta 10/06/2015].

MENÉNDEZ ROBLES, M.L. (2014): “El Greco, Vega Inclán y Huntington”, e-artDocuments, $\mathrm{n}^{\circ} 7$, pp.105-122.

MENÉNDEZ ROBLES, M.L. (2015): "Un mecenas atípico: el II Marqués de la Vega Inclán”, en El reverso de la historia del arte: exposiciones, comercio y coleccionismo (1850-1950). Gijón, Trea, pp. 201-212.

MERINO DE CÁCERES, J.M. (2011): “Arthur Byne, un expoliador de guante blanco”, en La dispersión de objets de arte fuera de España en los siglos XIX y XX. Barcelona, Publicacions i Edicions de la Universitat de Barcelona, Cádiz, Servicio de Publicaciones de la Universidad de Cádiz, pp. 241-272.

MONTPETIT, R. (1996): “Une logique d'exposition populaire: les images de la muséographie analogique", Publics et Musées, vol. 9, no 1, pp. 55-103.

MERINO DE CÁCERES, J.M. y MARTÍNEZ RUIZ, M.J. (2012): La destrucción del patrimonio artístico español: W. R Hearst: "el gran acaparador”. Madrid, Cátedra.

MORENO GARRIDO,A. (2004): Turismo y nación: la definición de la identidad nacional a través de los símbolos turísticos (España, 1908-1929). [Tesis] Universidad Complutense de Madrid.

MORENO GARRIDO, A. (2005): “Turismo de élite y administración turística de la época (1911-1936)", Estudios Turísticos, n. ${ }^{\circ}$ 163-164, pp. 31-54.

MORENO GARRIDO, A. (2007): Historia del turismo en España en el siglo XX. Madrid, Síntesis.

ORTEGA Y GASSET, J. (1922): Para un Museo Romántico. Madrid, Comisaría regia de Turismo.

ORTEGA, N. (2014): "Paisaje, patrimonio e identidad en la conformación de la primera política turística española”, Ería. Revista Cuatrimestral de Geografía, n 93, pp. 27-42. PÉREZ DE AYALA, R. (1991): “El Museo Romántico” [1922], en Ramón Pérez de Ayala y las artes plásticas. Granada, Fundación Rodríguez-Acosta, pp. 206- 209.

PÉREZ MATEO, S. y MARÍN TORRES, M.T. (2006): "Una visión del artista y el museo: las Wunderkammern de la postmodernidad”, en La Museología y la Historia del Arte. Murcia, Universidad de Murcia, pp. 285-322.

PÉREZ MATEO, S. (2007): "El mobiliario. Una aproximación a las colecciones del Museo del Greco", en Tesoros Ocultos. Fondos Selectos del Museo del Greco y del Archivo de la Nobleza. Madrid, Ministerio de Cultura, pp. 331-345. 
PÉREZ MATEO, S. (2016): Las casas museo en España. Análisis de una tipología museística singular. [Tesis] Universidad de Murcia.

PÉREZ MULET, F. y SOCIAS BATET, I. (Eds.) (2011): La dispersión de objets de arte fuera de España en los siglos XIX y XX. Barcelona, Publicacions i Edicions de la Universitat de Barcelona, Cádiz, Servicio de Publicaciones de la Universidad de Cádiz.

POLLÁN PALOMO, V. (2016): "La casa en la que vivió Cervantes en Valladolid", en Colecciones Cervantinas. Madrid, Ministerio de Educación, Cultura y Deporte, pp. 31-38.

PORIA, Y., BIRAN, A. y REICHEL, A. (2009): "Visitors preferences for interpretation at heritage sites", Journal of Travel Research, vol. 48, n 1, pp. 92-105.

POULOT, D. (1986): "Les mutations de la sociabilité dans les musées français et les stratégies des conservateurs, 1960-1980”, en Sociologie de l'art. París, Documentation Française, pp. 97-98.

PRENTICE, R. (2001): "Experimental cultural tourism: Museums and the marketing of new romanticism of evoked authenticity", Museum Management and Curatorship, $\mathrm{n}^{\circ}$ 1, pp. 5-26.

RIAÑO, J. F. (1872): "Introduction", en Classified and Descriptive Catalogue of the Art Objects of Spanish Productions in the South Kensington Museum. Londres, Her Majestry's Stationery Office.

RODRÍGUEZ MARCO, I.M. (2013): Period rooms, ¿una museografía obsoleta? . Trabajo Fin Máster UNED. [inédito].

RUIZ GÓMEZ, L. (2013): Guía del Museo del Greco. Madrid, Ministerio de Educación, Cultura y Deporte.

SERRANO GARCÍA, R.; SANZ BALLESTEROS, J. y COSO MARTÍN, M. A. (2007): "Museo Casa de Dulcinea, El Toboso. Toledo", en II Encuentro Internacional sobre Tecnologías en Museografía. ICOM España, pp. G3-G17.

SOCIAS BATET, I. y GKOZGKOU, D. (Eds.) (2013): Nuevas contribuciones en torno al mundo del coleccionismo de arte hispánico en los siglos XIX y XX. Gijón, Trea.

STORM, E. (2011): El descubrimiento del Greco: Nacionalismo y arte moderno (18601914). Madrid, Marcial Pons y Fundación El Greco 2014.

SUÁREZ-ZULOAGA, I. y KAGAN, R.L. (dir.) (2010): When Spain fascinated America. Madrid, Fundación Zuloaga.

TAINE, H. (1922): Filosofía del Arte (traducción de A. Cebrián). Madrid, Espasa Calpe.

TATCHER ULRICH, L. (2001): The Age of Homespun: Objects and Stories in the Creation of an American Myth. New York, Alfred A, Knopf.

TORRES GONZÁLEZ, B. (1998a): "El Museo Romántico: un museo de ambiente”, Revista del Museo Romántico, $\mathrm{n}^{\circ}$ 1, pp. 13-79.

TORRES GONZÁLEZ, B. (1998b): “El Marqués de la Vega-Inclán, coleccionista”, Goya, $\mathrm{n}^{\circ} 67, \mathrm{pp} .333-344$.

TORRES GONZÁLEZ, B. (1999a): "Exposición permanente sobre el fundador del Museo Romántico: Don Benigno de la Vega-Inclán”, Revista Museo Romántico, no 2 pp. 49-60.

TORRES GONZÁLEZ, B. (1999b): "El fundador del Museo Romántico: el marqués de la Vega-Inclán y el 98", en La España del 98: política, pensamiento y cultura en el fin de siglo. Madrid, Dykinson, pp. 141-155. 
TORRES GONZÁLEZ, B. (2006): “Plan Museológico del Museo Romántico”, Revista del Museo Romántico, $\mathrm{n}^{\circ}$ 5, pp. 13-143.

TORRES GONZÁLEZ, B. (2008): “Consideraciones sobre el nuevo plan museológico del Museo Romántico", Museo, nº 13, pp. 169-187.

TORRES GONZÁLEZ, B. (2009): Guía del Museo del Romanticismo. Madrid, Ministerio de Cultura.

TORRES GONZÁLEZ, B. (2010): "El Museo del Romanticismo", Amigos de los museos: boletín informativo, $\mathrm{n}^{\circ} 30, \mathrm{p} .36$.

TORRES GONZÁLEZ, B. (2009-2010): “Algunas consideraciones acerca del nuevo Museo Nacional del Romanticismo", Museos.es. Revista de la Subdirección General de los Museos Estatales, n ${ }^{\circ}$ 5-6, pp. 188-197.

TORRES GONZÁLEZ, B. (2013a): "El poder de los objetos”, en Casas museo: museología y gestión. Actas de los Congresos sobre Casas Museo (2006, 2007, 2008). Museo Nacional del Romanticismo. Madrid, Ministerio de Educación, Cultura y Deporte, pp. 183-194.

TORRES GONZÁLEZ, B. (2013b): “La casa del héroe. Dos ejemplos emblemáticos: Benigno Vega Inclán y Carmen de Burgos, "Colombine", en Casas museo: museología y gestión. Actas de los Congresos sobre Casas Museo (2006, 2007, 2008). Museo Nacional del Romanticismo. Madrid, Ministerio de Educación, Cultura y Deporte, pp. 217-240.

TORRES GONZÁLEZ, B. (2013c). "El Museo Nacional del Romanticismo. Una nueva narrativa museográfica”, en Casas museo: museología y gestión. Actas de los Congresos sobre Casas Museo (2006, 2007, 2008). Museo Nacional del Romanticismo. Madrid, Ministerio de Educación, Cultura y Deporte, pp. 72-88.

TRAVER TOMAS, V. (1965): El Marqués de la Vega-Inclán. Castellón, Dirección General de Bellas Artes, Fundaciones Vega-Inclán.

URREA, J. (2005): Historia y Guía del Museo Casa de Cervantes de Valladolid. Madrid, Ministerio de Cultura.

VAQUERO ARGÜELLES, L. (2013). "De casa a museo y de museo a casa”, en Casas museo: museología y gestión. Actas de los Congresos sobre Casas Museo (2006, 2007, 2008). Museo Nacional del Romanticismo. Madrid, Ministerio de Educación, Cultura y Deporte, pp. 135-144.

VEGA INCLÁN, M. (1928): “Madrid, Aranjuez, Toledo”, en Toledo. Guía Oficial (3ª ed.). Toledo, Rafael Gómez Menor, pp. 227-230.

VENTURI, L. (1982): Historia de la crítica de arte. Barcelona, Gustavo Gili.

VILLAVERDE, J. (2014): “¿Motor o lastre nacional? La controvertida actuación del Marqués de la Vega Inclán como Comisario Regio de Turismo 1911-1928”, en Actas del XII Congreso de Historia Contemporánea. Madrid. E.P.

WANG, N. (1999): "Rethinking authenticity in tourism experience", Annals of Tourism Research, vol. 26, n' 2, pp. 349-370.

WATTS, W.W. (1908): "Some uses of a museum of industrial art", Museums Journal, $\mathrm{n}^{\circ}$ 7, pp. 154-164. 
